\title{
An application of RASER technique in the treatment of chronic total occlusion accompanied with stent fracture in right coronary artery: a case report
}

\author{
Yajun Xue ${ }^{1 \dagger}$, Boda Zhou ${ }^{1+}$, Weimin Wang ${ }^{2}$, Guobin Miao ${ }^{1}$, Ou Zhang ${ }^{1}$, Jie Zhou', Yu Geng ${ }^{1}$, Yanlong Zhai ${ }^{1}$, \\ Chunhui Ren ${ }^{1}$ and Ping Zhang ${ }^{1 *}$ (D)
}

\begin{abstract}
Background: The interventional treatment of chronic total occlusion (CTO) with stent fracture as well as severe calcification was extremely difficult and no effective technique has been reported.

Case presentation: A 50-year-old woman was hospitalized for angina, angiography revealed triple vessel disease, CTO accompanied with stent fracture in right coronary artery (RCA). Treatment using conventional coronary intervention was expected to be difficult. Therefore, we performed RASER technique, which was a combination of excimer laser coronary atherectomy (ELCA) with rotational atherectomy (RA), followed by the deployment of drugeluting stents. Intravascular ultrasound (IVUS) revealed well attachment of the stents, the patient was discharged 3 days after the procedure and no recurrent chest discomfort was reported in a follow-up time of 10 months.
\end{abstract}

Conclusion: This case report provided a first report of RASER technique in the treatment of CTO with stent fracture and severe calcification.

Keywords: Excimer laser coronary atherectomy, Rotational atherectomy, Chronic total occlusions, RASER technique

\section{Background}

Although drug-eluting stent based intervention has become the most widely used treatment for coronary heart disease, a high incidence of in-stent restenosis after coronary stent implantation remains an important challenge [1]. Previous studies demonstrated that rotational atherectomy (RA) is safe and effective to treat stent restenosis $[2,3]$. Meanwhile, excimer laser coronary atherectomy (ELCA) has a long history of adjunctive therapy that can be applied to treat in-stent restenosis (ISR) [4]. However, in particular case of complicated CTO after ISR, microcatheter and Rota Wire could not pass the lesion, makes the operation difficult. The RASER technique combines ELCA with RA, since ELCA could provide an upstream channel to permit microcatheter and Rota Wire passage,

\footnotetext{
* Correspondence: zpa00593@btch.edu.cn

†Yajun Xue and Boda Zhou contributed equally to this work.

${ }^{1}$ Department of Cardiology, Beijing Tsinghua Changgung Hospital, Beijing

102218, China

Full list of author information is available at the end of the article
}

while RA could fully debulk the lesion [5]. Unfortunately, there is no report regarding combination of ELCA and RA in CTO accompanied with stent fracture. In the current report, we described a novel application of RASER technique to successfully treat in-stent occlusion accompanied with stent fracture in RCA.

\section{Case report}

A 50-year-old woman was hospitalized on October, 2017 for ongoing limiting angina pectoris. The patient had a history of precordial chest pain for 4 years, and aggravation for 1 week. Four years ago, she was diagnosed unstable angina pectoris and old anterior myocardial infarction at local hospital. Angiography revealed triple vessel disease involving proximal LAD, middle LCX and middle RCA (Fig. 1), The patient underwent percutaneous coronary intervention (PCI) with 3 drug eluting stents (DESs) $(2.5 \mathrm{~mm} \times 33 \mathrm{~mm}, 2.5 \mathrm{~mm} \times 18 \mathrm{~mm}$ and $2.5 \mathrm{~mm} \times 23 \mathrm{~mm})$ in RCA, and $1 \mathrm{DES}(3 \mathrm{~mm} \times 38 \mathrm{~mm})$ 

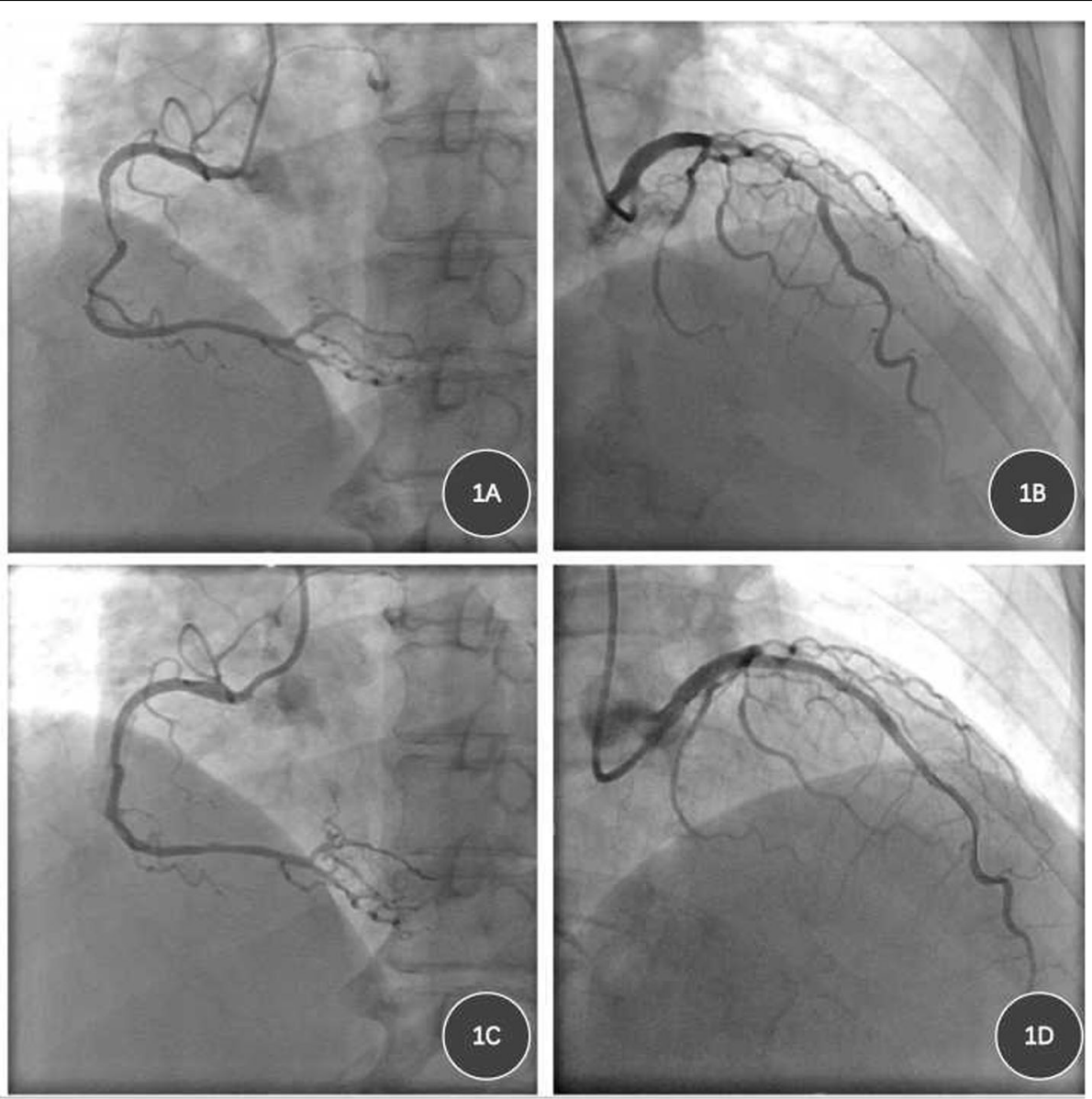

Fig. 1 Images of coronary angiography and $\mathrm{PCl} 4$ years ago. $\mathbf{a}$, severe and diffused stenosis in the middle segment of RCA; $\mathbf{b}$, severe and diffused stenosis in the proximal segment of $L A D$; $\mathbf{c}$, postoperative angiography of RCA; $\mathbf{d}$, postoperative angiography of $L A D$

in the LAD (Fig. 1). The patient's symptoms relived after PCI, while secondary prevention medications were taken regularly (clopidogrel was stopped after one and a half years, aspirin continued). Past medical history includes type 2 diabetes for 21 years, hyperlipidemia for 4 years, left renal artery stenosis and underwent stenting for 1 year, diabetic foot necrosis and underwent left foot amputation for 5 months. She has no family history of coronary heart disease.

After hospitalization, physical examination was nonremarkable, and secondary prevention treatment was prescribed, troponin was negative, echocardiography revealed LVEF $45 \%$. Coronary angiography revealed visible stents in the proximal and middle segments of RCA, with in-stent total occlusion (Fig. 2a), stent fracture could be seen at the second turning point of RCA (Fig. 2c and d). Stent was seen in proximal LAD, with mild intimal hyperplasia in the stent $(50-60 \%$ diffused stenosis), $50-70 \%$ diffused stenosis in middle LCX and $70-85 \%$ diffused stenosis in proximal and middle of second obtuse marginal artery (OM2) (Fig. 2b). The patient was diagnosed unstable angina pectoris and old anterior myocardial infarction, and PCI was indicated.

As the ISR of RCA was CTO, which accompanied stent fracture, two difficulties present: (1)it will be hard for the guidewire to traverse the lesion through true lumen. (2)balloon expansion in the stent fracture region was expected to be difficult. Therefore, we performed transradial PCI using 6F AL1.0 guiding catheter, after GAIA second guidewire (Asahi Intec, Abbott Vascular, Rangendingen, Germany) traversed the lesion, neither microcatheter nor balloon anchored guidewire could pass the leision, so we used a $1.4 \mathrm{~mm}$ ELCA catheter (CVX-300, Spectranetics, CO, USA) with a pulse rate of $40 \mathrm{~Hz}$ and energy output of $45 \mathrm{~mJ} / \mathrm{mm}^{2}$ to ablate ISR for 3 times (Fig. 3d). Then a Finecross MG catheter (Terumo Medical Corp., NJ, USA; 1.8 Fr) was applied to exchange for the Rota Wire, so that Rota Wire could be easily advanced to distal RCA. Then, RA was performed using a $1.25-\mathrm{mm}$ burr (RotaLink, Boston Scientific) at the speed of $170,000 \mathrm{r} / \mathrm{min}$ for $75 \mathrm{~s}$ to fully debulk the lesion (Fig. 3e and f), IVUS showed $90^{\circ}-270^{\circ}$ calcification 

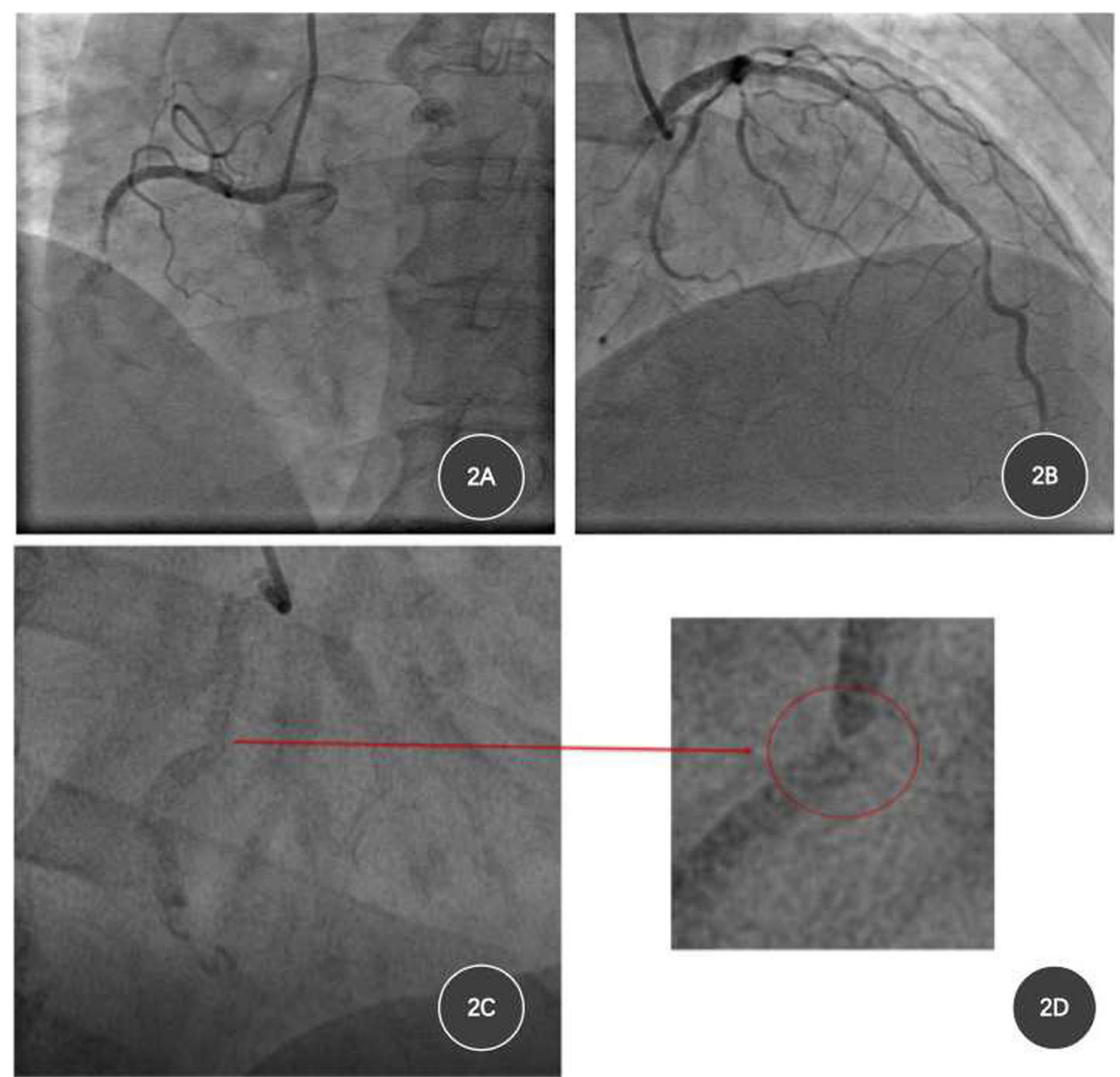

Fig. 2 Images of coronary angiography after hospitalization. a, stents in proximal and middle RCA, total occlusion in middle RCA; b, stent in proximal LAD, accompanied with mild intimal hyperplasia in stent, 50-70\% diffused stenosis in middle LCX and 70-85\% diffused stenosis in proximal and middle $\mathrm{OM} 2$; $\mathbf{c}$ and $\mathbf{d}$, stent fracture at the second turning point of RCA

and stent fracture (Additional file 1: Figure S1), followed by the deployment of one drug-eluting stent $\left(2.75 \mathrm{~mm}^{*} 24 \mathrm{~mm}\right.$, Fig. 4a and b). Intravascular ultrasound (IVUS) revealed well attachment of the stent (Fig. 4c and d), and the patient was discharged without complication 3 days later, echocardiography revealed LVEF 60\%(Additional file 2: Figure S2). The patient was followed up for 10 months and no recurrent chest discomfort was reported, no adverse event was reported, echocardiography revealed LVEF $64 \%$.

\section{Discussion and conclusion}

In this case, we successfully performed RASER technique using ELCA for ISR ablation combined with RA for rotational ablation in a patient with CTO in RCA accompanied with stent fracture. The RASER technique achieved excellent angiographic and IVUS result, the patient recovered well after the procedure and was discharged 3 days later.

ELCA is a long-established adjunctive therapy that can be applied during complicated PCI. The indications of ELCA during PCI include thrombus, non-crossable or non-expandable lesions, chronic total occlusions, instent restenosis and stent under-expansion [6]. The key advantage of ELCA over alternative atherectomy interventions is delivery on a standard 0.014-in. guidewire. The major limitation of ELCA is incompetency to ablate heavy calcification. In our case, CTO in RCA accompanied with stent fracture. Microcatheter could not pass the occlusion, indicating fibro-calcific nature of the lesion, which makes balloon dialation and rota ablation impossible. ELCA successfully created a channel after guidewire traversed the CTO lesion, which facilitated the passage of microcatheter and subsequent exchange of Rota Wire with guidewire. As the lesion was severely calcific, rotational atherectomy was necessary to fully debulk the lesion.

It was reported that longitudinal stent ablation by RA with a $1.75-\mathrm{mm}$ burr was effective in treating underexpanded stent in CTO lesion with severe calcification [7]. However, inability of Rota Wire to pass the lesion was a major problem. In addition, ELCA has been recognized as an alternative to treat ISR [8], but severe calcific 


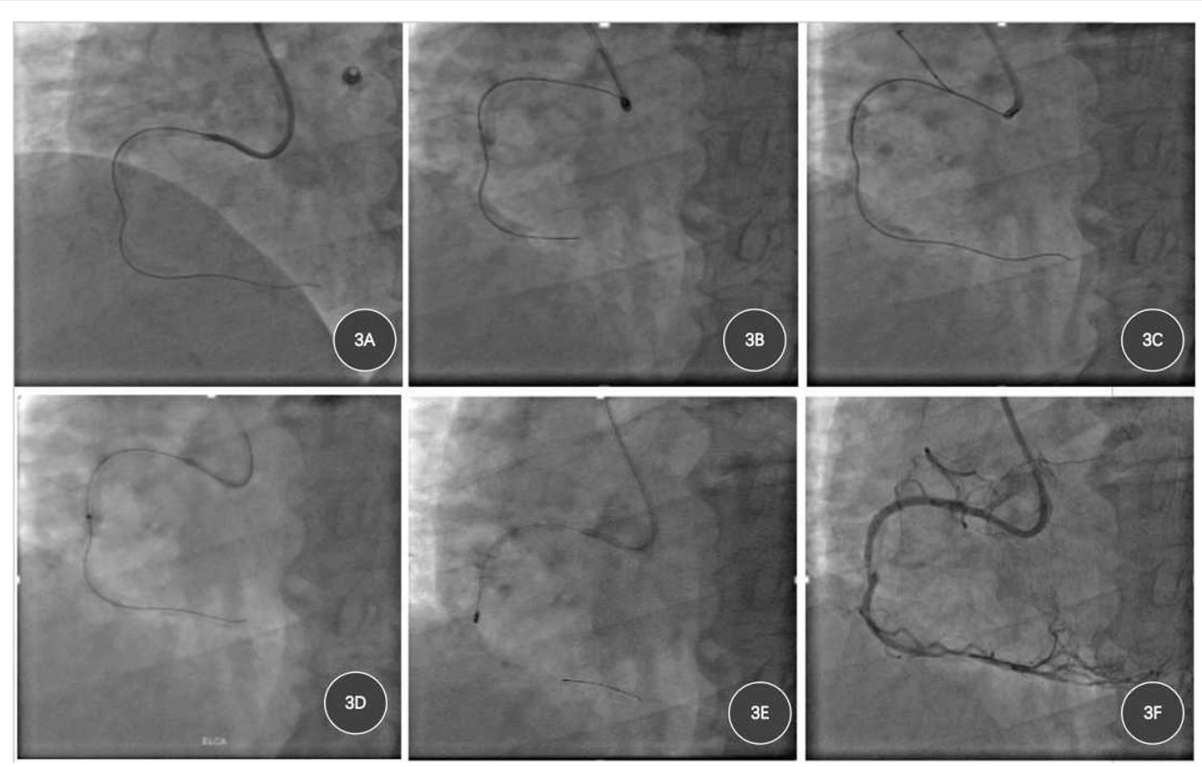

Fig. 3 Coronary intervention process in RCA. a, GAIA second guidewire traversed the CTO lesion in RCA; $\mathbf{b}$, Finecross microcatheter could not pass the occlusion, nor could Corsair microcatheter; $\mathbf{c}$, application of balloon anchored guidewire technique still failed to pass the occlusion; $\mathbf{d}$, ELCA was performed using a 1.4-mm burr excimer laser catheter to ablate in-stent occlusion; e, RA was performed using a 1.25-mm burr RotaLink at a speed of 170,000 r/min; f, coronary angiography after ELCA and rotational ablation
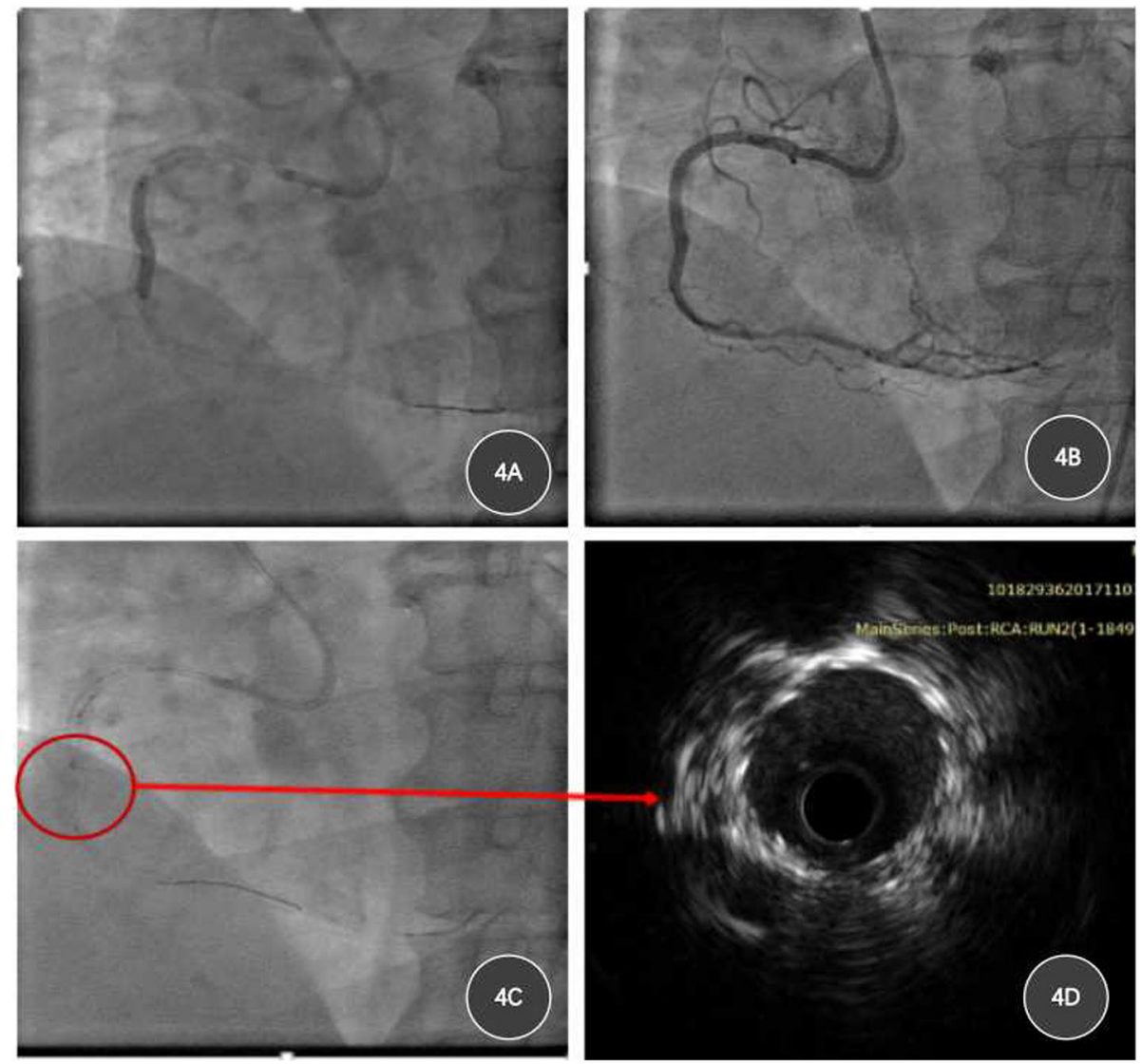

Fig. 4 Stent implantation and IVUS examination of RCA. a, a 2.75 mm*24 mm DES was deployed in RCA; b, coronary angiography after the deployment of stent; $\mathbf{c}$ and $\mathbf{d}$ IVUS revealed well attachment of stent to the vessel wall 
lesion frequently led to unsatisfactory result treating with ELCA. Therefore, RASER technique, a combination of ELCA and RA was the optimal choice for CTO lesion with severe calcification. However, the application of RASER in CTO with stent fracture as well as severe calcification has not been reported before, our case received a satisfactory result.

The ELCA catheters can be delivered with a standard 0.014 " guidewire and $0.9 \mathrm{~mm}, 1.4 \mathrm{~mm}, 1.7 \mathrm{~mm}$, and 2.0 $\mathrm{mm}$ catheters are available. Studies showed that 0.9 and $1.4 \mathrm{~mm}$ catheters are more frequently used in CTO cases [9]. In the present case, we performed a 1.4-mm burr excimer laser catheter with a pulse rate of $40 \mathrm{~Hz}$ and energy output of $45 \mathrm{~mJ} / \mathrm{mm}^{2}$ to ablate occlusion for 3 times. Alternatively, a $0.9-\mathrm{mm}$ ELCA catheter is suggested when the lesion is severely occluded accompanied with calcification [10].

In summary, this is the first report of successful application of RASER technology in patients with CTO accompanied with severe calcification and stent fracture. This case report may extend ELCA indications and provide a novel approach to complicated PCI. Eventually, with the increase of cases and the accumulation of experience, patients who were unable to undergo conventional PCI will benefit.

\section{Supplementary information}

Supplementary information accompanies this paper at https://doi.org/10. 1186/s12872-019-1258-1.

Additional file 1: Figure S1. IVUS examination of RCA after RASER technique.

Additional file 2: Figure S2. Representative images of

echocardiography before and 3 days after intervention.

\section{Abbreviations}

CTO: Chronic total occlusion; DES: Drug eluting stent; ELCA: Excimer laser coronary atherectomy; ISR: In-stent restenosis; IVUS: Intravascular ultrasound; OM2: Second obtuse marginal; PCl: Percutaneous coronary intervention: RA: Rotational atherectomy; RCA: Right coronary artery

\section{Acknowledgements}

Not applicable.

\section{Authors' contributions}

$Y X, W W, G M, O Z, J Z, Y G, Y Z, C R$ performed $P C I, Y X, B Z$ and $P Z$ wrote the paper. All authors have read and approved the manuscript.

\section{Funding}

Yajun Xue received funding from State Key Laboratory of Low-Dimensional Quantum Physics, Tsinghua University (KF201608). Yajun Xue performed PCI and wrote the paper, grant KF201608 supported collection, analysis, interpretation of data. Boda Zhou received funding from National Natural Science Foundation of China (81970299). Boda Zhou wrote the paper, grant 81970299 supported collection, analysis, interpretation of data.

\section{Availability of data and materials}

Data sharing is not applicable to this article as no datasets were generated or analysed during the current study.
Ethics approval and consent to participate

The study was approved by the ethics committee of Beijing Tsinghua Changgung Hospital, the patient gave writen consent to participate in the study.

Consent for publication

Writen informed consent for publication was obtained from the patient.

\section{Competing interests}

The authors declare that they have no competing interests.

\section{Author details}

${ }^{1}$ Department of Cardiology, Beijing Tsinghua Changgung Hospital, Beijing 102218, China. ${ }^{2}$ Department of Cardiology, Peking University People's Hospital, Beijing 010010, China.

Received: 15 October 2018 Accepted: 13 November 2019

Published online: 29 November 2019

\section{References}

1. Kim MS, Dean LS. In-Stent Restenosis. Cardiovasc Ther. 2011;29(3):190-8.

2. Kawata M, Kato Y, Takada H, Kamemura K, Matsuura A, Sakamoto S. Successful rotational atherectomy for a repetitive restenosis lesion with underexpansion of double layer drug-eluting stents due to heavily calcified plaque. Cardiovasc Interv Ther. 2016;31(1):65-9.

3. Rissanen TT, Uskela S, Siljander A, Kärkkäinen JM, Mäntylä P, Mustonen J, Eränen J. Percutaneous coronary intervention of complex calcified lesions with drug-coated balloon after rotational Atherectomy. J Interv Cardiol. 2017;30(2):139-46

4. Ichimoto E, Kadohira T, Nakayama T, De Gregorio J. TCT-800 long-term target lesion revascularization after treatment with Excimer laser coronary Atherectomy for in-stent restenosis of drug-eluting stent. J Am Coll Cardiol. 2017;70(18 Supplement):B325.

5. Rawlins J, Din JN, Talwar S, O'Kane P. Coronary intervention with the excimer laser: review of the technology and outcome data. Intervent Cardiol Rev. 2016;11(1):27.

6. Rawlins J, Din JN, Talwar S, O'Kane P. Coronary intervention with the Excimer laser: review of the technology and outcome data. Interv Cardiol. 2016;11(1):27-32.

7. Koide M, Inoue K, Matsuo A, Fujita H. Optical coherence tomography findings after longitudinal ablation for an underexpanded stent in a heavily calcified lesion: a case report. BMC Cardiovasc Disord. 2016;16(1):241.

8. Rawlins J, Talwar S, Green M, O'Kane P. Optical coherence tomography following percutaneous coronary intervention with Excimer laser coronary atherectomy. Cardiovasc Revasc Med. 2014;15(1):29-34.

9. Badr S, Ben-Dor I, Dvir D, Barbash IM, Kitabata H, Pendyala LK, Loh JP, Torguson R, Pichard AD, Waksman R. The state of the excimer laser for coronary intervention in the drug-eluting stent era. Cardiovasc Revasc Med. 2013:14(2):93-8

10. Hou F-J, Zhou Y-J, Liu W, Guo Y-H, Yang S-W, Ohene BE, Wang Z-Z, Guan J. Application of Excimer laser coronary Atherectomy guided by optical coherence tomography in the treatment of a severe calcified coronary lesion. Chin Med J. 2018;131(8):1001.

\section{Publisher's Note}

Springer Nature remains neutral with regard to jurisdictional claims in published maps and institutional affiliations.

Ready to submit your research? Choose BMC and benefit from:

- fast, convenient online submission

- thorough peer review by experienced researchers in your field

- rapid publication on acceptance

- support for research data, including large and complex data types

- gold Open Access which fosters wider collaboration and increased citations

- maximum visibility for your research: over $100 \mathrm{M}$ website views per year

At $\mathrm{BMC}$, research is always in progress.

Learn more biomedcentral.com/submission 